\title{
USO DE CLORO ELECTROGENERADO A PARTIR DE NaCI EN MEDIO ÁCIDO COMO UNA PROPUESTA PARA LA LIXIVIACIÓN DE ORO ALUVIAL
}

\author{
Ulises Quiroz Aguinaga ${ }^{a}$, Angélica María Baena Moncada ${ }^{a}$, \\ Adolfo La Rosa-Toro Gómez ${ }^{* a}$
}

\begin{abstract}
RESUMEN
La electrogeneración anódica de cloro molecular, a partir de cloruro de sodio en una celda electrolítica, permite la producción de ácido hipocloroso en medio acuoso. Esta mezcla de cloruro y ácido hipocloroso actúa como lixiviante del oro aluvial hasta sus formas complejas, $\left[\mathrm{AuCl}_{2}\right]^{-},\left[\mathrm{AuCl}_{4}\right]^{-}$. Las cantidades óptimas para la lixiviación de oro, empleando solo $\mathrm{NaCl}$ acuoso en medio neutro fue de $10 \mathrm{~g} \mathrm{~L}^{-1}$, mientras que a $\mathrm{pH} 2$, con una concentración fija de $\mathrm{NaCl}$ de $10 \mathrm{~g} \mathrm{~L}^{-1}$ la lixiviación de oro aumentó hasta en un 70,4\%. El agregado de hipoclorito de sodio a una solución de cloruro de sodio a $\mathrm{pH} 2$ demuestra que es el producto oxidado del cloruro el que cumple la función de oxidante y puede ser empleado exitosamente para recuperar oro de las arenas aluviales sin el empleo de mercurio.
\end{abstract}

Palabras clave: lixiviación ecológica, cloruro/hipoclorito, electrolixiviación, oro aluvial

\section{USE OF CHLORINE ELECTROGENERATED FROM NaCI IN ACID MEDIUM AS A PROPOSAL FOR THE LEACHING OF ALLUVIAL GOLD}

\begin{abstract}
Anodic electrogeneration of molecular chlorine from sodium chloride in an electrolytic cell produces a hypochlorous acid solution in an aqueous medium. This mixture of chloride and hypochlorous was used to leach gold from alluvial ore to its complex forms, $\left[\mathrm{AuCl}_{2}\right]^{-}$, $\left[\mathrm{AuCl}_{4}\right]^{-}$. The optimal amounts of $\mathrm{NaCl}$ in a neutral medium for gold leaching was $10 \mathrm{~g} \mathrm{~L}^{-1}$, while at $\mathrm{pH} 2$, with a fixed $\mathrm{NaCl}$ concentration of $10 \mathrm{~g} \mathrm{~L}^{-1}$ it was observed a gold leaching increment of $70.4 \%$. The addition of sodium hypochlorite to a solution of sodium chloride at $\mathrm{pH} 2$ shows that it is the chloride oxidized product that performs the function of oxidant and can be used successfully for gold recovering from alluvial ore without the use of mercury.
\end{abstract}

Key words: ecological leaching, chloride / hypochlorite, electrowinning, alluvial gold

\footnotetext{
${ }^{a}$ Laboratorio de Investigación de Electroquímica Aplicada (GIEA) de la Facultad de Ciencias de la Universidad Nacional de Ingeniería, Av. Túpac Amaru 210, Rímac, Lima-Perú

*toro@uni.edu.pe
} 


\section{INTRODUCCIÓN}

La producción de oro artesanal (oro aluvial) en el Perú está representado por los departamentos de Puno, Arequipa, Piura y Madre de Dios, principalmente. En dichos lugares la extracción de oro artesanal utiliza comúnmente mercurio para su amalgamación y posterior eliminación de este por medio de un calentamiento, lo que conlleva a que el mercurio se encuentre no solo en el aire, sino también en el agua y suelo'.

El alto uso de mercurio en Madre de Dios, por parte de la minería artesanal formal e informal, principalmente, está afectando a las reservas naturales y está causando graves daños en la salud de los pobladores ${ }^{2}$. Se estima que alrededor de 30000 mineros artesanales hay en Madre de Dios en la actualidad ${ }^{1}$.

En las últimas décadas se han realizado trabajos de investigación orientados a encontrar sustancias químicas alternativas al empleo de mercurio y/o cianuro para la extracción de oro. G. Senanayake et al. ${ }^{3}$ realizaron una revisión pormenorizada de las diferentes alternativas al cianuro para la lixiviación de oro, entre ellas se citan el empleo de la tiourea, el tiocianato, amoniaco y otros cuya toxicidad es evidente y en Perú se encuentra regulada por los Estándares de Calidad Ambiental (ECA). El uso de cloruro/hipoclorito para lixiviar oro data de antes de 1887, sin embargo, cayó en desuso debido a la corrosión asociada al cloruro, no obstante, hoy existen materiales que pueden eliminar este problema. Publicaciones de los últimos años, hacen referencia al empleo de cloruro-hipoclorito constituyéndose en una interesante propuesta no contaminante. El cloruro de sodio e hipoclorito han sido empleados para lixiviar oro de minerales conteniendo pirita, obteniendo cloruro aúrico ${ }^{4-7}$. La electrolisis de cloruro de sodio se ha utilizado para generar hipoclorito, logrando lixiviar oro de la amalgama de mercurio ${ }^{8,9}$.

En este trabajo de investigación se ha realizado la lixiviación de oro aluvial a partir de la electrolisis de una solución de $\mathrm{NaCl} / \mathrm{NaClO}$ a $\mathrm{pH}$ ácido logrando un porcentaje de recuperación del oro de 99,93 y $99,89 \%$.

\section{PARTE EXPERIMENTAL}

\section{Preparación de la muestra}

La toma de muestra de la arena aluvial se realizó en la concesión minera "La Familia" del bajo Puquiri, perteneciente al departamento de Madre de Dios; el lugar se encuentra aproximadamente a cinco horas en vehículo desde Madre de Dios.

La muestra de arenilla de oro fue homogenizada por medio de roleo; operación que consiste en poner la muestra en una lona y luego tomar alternadamente la lona por las esquinas opuestas, con el propósito de mezclar las partículas. A continuación, se realizó el cuarteo de la muestra; operación que consiste en dividir en cuatro secciones y tomar dos al azar y proceder a mezclarlos, de esta porción se tomó la muestra para la realización de los ensayos 
fisicoquímicos. La muestra obtenida fue llevada a una mesa gravimétrica para separar el contenido de oro de la arenilla y analizarlos por separado. Las partes se denominarán oro aluvial y arenilla. La relación de separación fue de $0,86 \mathrm{~g} \mathrm{Au} \mathrm{Kg}^{-1}$ de arenilla aluvial tratada

\section{Caracterización fisicoquímica de la muestra de arenilla}

Se realizó la caracterización mineralógica de la muestra de arenilla para conocer los componentes del material en estudio y asociar posibles efectos inhibidores en el proceso de lixiviación. La caracterización se realizó mediante la visualización de la muestra usando una lupa estereoscópica trinocular Nikón SMZ-745T. Adicionalmente, se realizó un análisis mineralógico semicuantitativo de todos los minerales presentes (fases cristalinas) con un límite de detección (L.D.) de 1,00 \%, a partir del procedimiento de validación del método por difracción de rayos X con Difractómetro D8 Advance Tubo Co $(38 \mathrm{kV}, 25 \mathrm{~mA})$ : KAlfa1: 6930.48eV KAlfa2: $1.7891 \AA$ A, Filtro: Kbeta: Ni.

\section{Análisis de oro aluvial por ensayo químico}

El análisis del oro aluvial se realizó por la metodología Fire Assay (Vía Seca). Esta metodología, utilizada para la determinación cuantitativa de oro, consiste en mezclar la muestra con agentes fundentes que incluyen el óxido de plomo (litargirio) y que se funden a alta temperatura. El óxido de plomo se reduce a plomo, el cual colecta el metal precioso. Cuando la mezcla fundida se enfría, el plomo permanece en el fondo, mientras que una escoria vítrea permanece en la parte superior. Los metales preciosos se separan del plomo mediante un procedimiento llamado copelación. El contenido de metal precioso colectado se procesa mediante digestión, sometiendo al regulo a un ataque ácido, se analiza mediante espectrómetro de absorción atómica.

\section{Análisis de oro remanente en la arenilla}

Para la determinación del contenido de oro remanente en la arenilla, el cual proviene de la separación previa de las partículas de oro empleando mesa gravimétrica, se analizó lixiviando el oro remanente con cianuro de sodio diluido, para este propósito se tomó una muestra de $100 \mathrm{~g}$ de arenilla a la cual se le adicionó $200 \mathrm{~mL}$ de una solución de 300 ppm de $\mathrm{NaCN}$, se ajustó el $\mathrm{pH}$ al valor de 12 con adiciones de solución de $\mathrm{NaOH} 4 \mathrm{~mol} \mathrm{~L}^{-1}$, posteriormente se agitó por $24 \mathrm{~h}$ y luego se dejó en reposo durante $72 \mathrm{~h}$ a temperatura ambiente, transcurrido el tiempo, la solución se separó por filtración y una muestra fue analizada por espectrofotometría de absorción atómica (EAA).

\section{Caracterización electroquímica - Estudio de la corrosión de oro patrón y parámetros de lixiviación \\ Caracterización electroquímica del oro patrón}

Para los estudios de corrosión electroquímica del oro, se utilizó un disco de electrodo de oro patrón de $0,08 \mathrm{~cm}^{2}$ de área, el cual fue limpiado previamente, tratando la muestra con ácido nítrico concentrado durante $5 \mathrm{~min}$, posteriormente se lavó con agua destilada, para luego ser sumergido en una solución de $\mathrm{H}_{2} \mathrm{SO}_{4} / \mathrm{H}_{2} \mathrm{O}_{2}$, por último, se realizó un lavado con agua destilada. 


\section{Estudio de la electrolixiviación del oro patrón}

Los estudios del comportamiento del oro en la solución lixiviante se realizaron empleando oro patrón (pureza 99,95\%). Los experimentos se llevaron a cabo en una celda de tres electrodos, utilizando como electrodo de trabajo el electrodo de oro patrón, como electrodo auxiliar un electrodo de grafito de elevada área superficial y como referencia un electrodo de Ag/ $\mathrm{AgCl}$ saturado en $\mathrm{KCl}$. Las medidas se realizaron utilizando un Potenciostato-Galvanostato PalmSens. Se utilizó como electrolito soporte $\mathrm{Na}_{2} \mathrm{SO}_{4} 0.1 \mathrm{~mol} \mathrm{~L}^{-1}$, la solución fue burbujeada previamente con gas nitrógeno durante $10 \mathrm{~min}$ a fin de eliminar el oxígeno disuelto. Las mediciones fueron realizadas empleando la técnica de voltamperometría cíclica en una ventana de potencial de 0 a $1,5 \mathrm{~V}$ vs $\mathrm{Ag} / \mathrm{AgCl}$ y a una velocidad de barrido de $100 \mathrm{mV} \mathrm{s}^{-1}$. Durante las mediciones se realizaron adiciones sucesivas de $\mathrm{NaCl}$ desde 1000 a 10000 ppm con el objetivo de medir los cambios frente al producto oxidado del cloruro, posteriormente se estudió el efecto del $\mathrm{pH}$, adicionando alícuotas de $\mathrm{HCl}$ 1:1 para acondicionar el $\mathrm{pH}$ a valores de 2, 3, 4, 5 y 7 en cada medición.

La electrolixiviación de oro en el electrolito de $\mathrm{NaCl} / \mathrm{NaClO}$ fue estudiado a diferentes valores de acidez. Para llevar a cabo este experimento se utilizó una solución de $\mathrm{NaCl}$ de 10000 ppm y $\mathrm{NaClO} 40000$ ppm, a la cual se le adicionaron diferentes concentraciones de $\mathrm{HCl}$ diluido 1:1 para ajustar el $\mathrm{pH}$ a valores de 2, 3 y 4 .

Se preparó una solución lixiviada de oro empleando muestras de oro patrón y oro de origen aluvial en solución de $\mathrm{NaCl} / \mathrm{NaClO}$ ajustada a $\mathrm{pH} 2$ sobre el cual se hizo los estudios de eficiencia de recuperación de oro.

\section{Eeficiencia de recuperación de oro patrón y de oro aluvial Método químico: Precipitación}

Se llevó a cabo estudios comparativos para estudiar la eficiencia de recuperación del oro patrón frente al oro de origen aluvial, empleando una solución de sulfato ferroso a $\mathrm{pH} 2$ conteniendo $16 \mathrm{~g} \mathrm{~L}^{-1}$, el $\mathrm{pH}$ se reguló con ácido fosfórico diluido 1:1. En la tabla 1 se muestra los datos de oro empleado en cada caso.

Tabla 1. Masas y volúmenes utilizados en la preparación de las disoluciones.

\begin{tabular}{ccc}
\hline & $\begin{array}{c}\text { Oro Patrón } \\
(\mathbf{9 9 , 9 5 \% )}\end{array}$ & $\begin{array}{c}\text { Oro Aluvial } \\
\mathbf{( 8 0 , 7 6 \% )}\end{array}$ \\
\hline Masa $(\mathrm{g})$ en \\
solución \\
$\begin{array}{c}\text { Volumen solución } \\
\text { madre }(\mathrm{mL})\end{array}$ & 0.50047 & 0.57613 \\
\hline
\end{tabular}


El estudio de eficiencia en la recuperación de oro se realizó tomando muestras de $25 \mathrm{~mL}$ de la solución madre a las cuales se le agregó la cantidad necesaria de solución de $\mathrm{FeSO}_{4}$, en continua agitación para asegurar la completa precipitación de oro. El punto final se determinó por ausencia de precipitado en una muestra de solución sobrenadante, culminada esta etapa se dejó en agitación durante 30 min y luego en reposo por 2 h para permitir la aglomeración del oro precipitado y a continuación se procedió a separar y lavar en agua ultrapura el sólido mediante filtración. El oro recolectado se secó en una estufa a $120^{\circ} \mathrm{C}$ durante $2 \mathrm{~h}$, se pesó y almacenó. En la tabla 2 se muestran los datos del proceso.

Tabla 2. Datos utilizados en la precipitación del oro.

\begin{tabular}{ccc}
\hline & $\begin{array}{c}\text { Oro Patrón } \\
\mathbf{( 9 9 , 9 5 \% )}\end{array}$ & $\begin{array}{c}\text { Oro Aluvial } \\
\mathbf{( 8 0 , 7 6 ~ \% )}\end{array}$ \\
\hline Concentración de solución $\left(\mathrm{g} \mathrm{mL}^{-1}\right)$ & 0.0050047 & 0.0057613 \\
Volumen de muestra utilizada $(\mathrm{mL})$ & 25 & 25 \\
Volumen $(\mathrm{mL})$ gastado de $\mathrm{FeSO}_{4}$ & 32 & 36 \\
$\left(0.016 \mathrm{~g} \mathrm{~mL}^{-1}\right)$ & & \\
\hline
\end{tabular}

\section{Método electroquímico: Electrodeposición}

En esta técnica se emplea una celda de dos electrodos sin compartimientos separados. Se utiliza un electrodo de acero inoxidable como cátodo de 2 x $2,5 \mathrm{~cm}$ de lado y un electrodo de grafito como ánodo inerte. La solución lixiviada se colocó en la celda bajo continua agitación en todo el proceso de electrolisis. Se utilizó una fuente de corriente con potencial regulable.

\section{RESULTADOS Y DISCUSIÓN}

\section{Caracterización fisicoquímica de la arenilla aluvial}

El oro proveniente de la muestra de arenilla fue previamente separado mediante operación en mesa gravimétrica. En la figura 1A) se observa la muestra de arenilla, a la cual se le realizó la caracterización mineralógica para conocer los componentes mayoritarios. La caracterización se realizó mediante visualización de la muestra usando una lupa estereoscópica trinocular como se observa en la figura 1B), las características mineralógicas de los posibles componentes se presentan en la tabla 3 . 

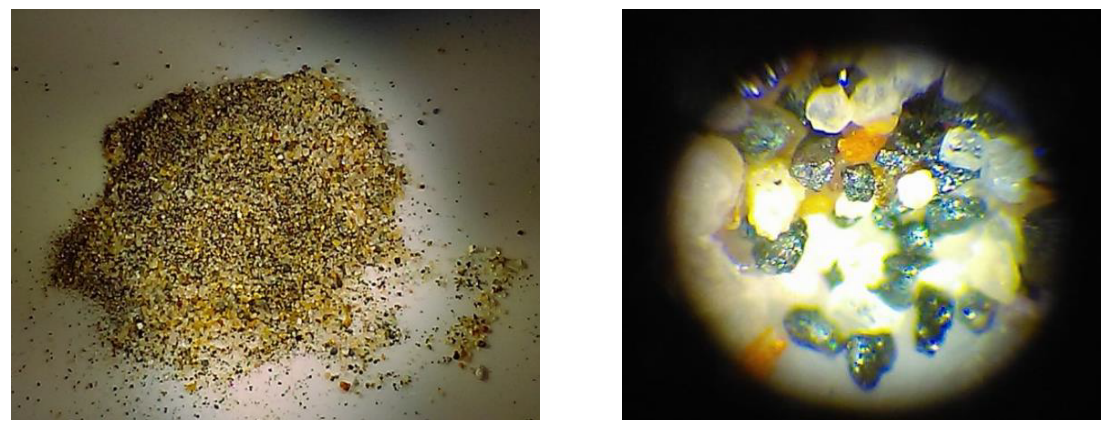

Figura 1. A) Muestra de arenilla. B) Imágenes de la muestra de arenilla con la lupa estereoscópica trinocular.

Tabla 3. Lista de posibles componentes en la muestra de arenilla.

\begin{tabular}{cc}
\hline Componente & Color \\
\hline Cuarzo $\left(\mathrm{SiO}_{2}\right)$ & Blanco \\
Magnetita $\left(\mathrm{Fe}_{3} \mathrm{O}_{4}\right)$ & Negro brilloso \\
Malaquita $\left(\mathrm{Cu}_{2} \mathrm{CO}_{3}(\mathrm{OH})_{2}\right)$ & Verde \\
Calcita $\left(\mathrm{CaCO}_{3}\right)$ & Blanco \\
Azufre & Amarillo \\
Otros & $\ldots$ \\
\hline
\end{tabular}

El análisis de la estructura y componente mineralógico semicuantitativo de la muestra fue analizada mediante difracción de rayos X (DRX), las líneas de difracción asociadas a los componentes mineralógicos se muestran en la figura 2. En la tabla 4 se presenta los resultados del análisis mineralógico expresado en porcentaje en masa relativa $(\mathrm{g} / \mathrm{g})$ de la muestra de arenilla.

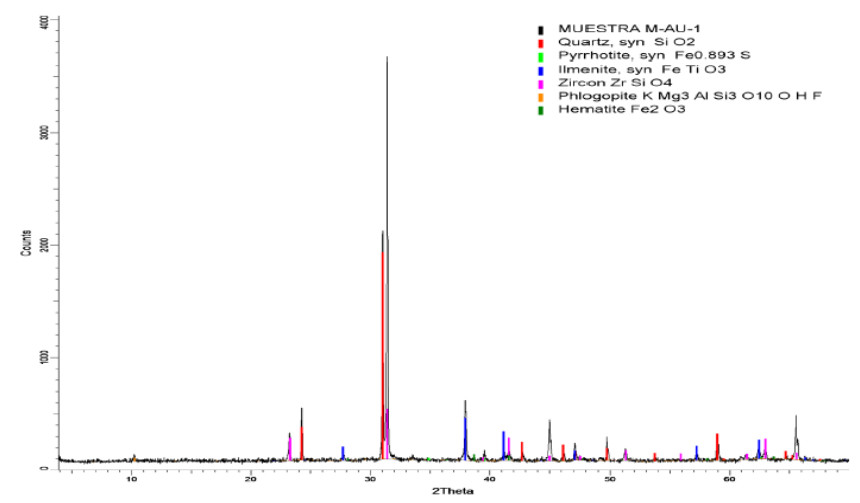

Figura 2. Difractograma de la muestra de arenilla. 
Uso de cloro electrogenerado a partir de nacl en medio ácido como una propuesta para la lixiviación de oro... 445

Tabla 4. Resultado del análisis mineralógico por DRX de la muestra de arenilla.

\begin{tabular}{ccc}
\hline Nombre del mineral & Fórmula general & Resultado aproximado (\%) \\
\hline Cuarzo & $\mathrm{SiO}_{2}$ & 44 \\
Zircón & $\mathrm{ZrSiO}_{4}$ & 39 \\
Ilmenita & $\mathrm{FeTiO}_{3}$ & 14 \\
Hematita & $\mathrm{Fe}_{2} \mathrm{O}_{3}$ & 1 \\
Pirrotita & $\mathrm{Fe}_{1-\mathrm{x}} \mathrm{S}$ & 1 \\
Flogopita & $\mathrm{KMg}_{3}\left(\mathrm{Si}_{3} \mathrm{Al}\right) \mathrm{O}_{10}(\mathrm{~F}, \mathrm{OH})_{2}$ & $<\mathrm{L} . \mathrm{D}$ \\
\hline
\end{tabular}

L.D.: Límite de detección

\section{Análisis de oro aluvial por ensayo químico}

El oro de origen aluvial, separado de la arenilla en mesa gravimétrica, fue analizado por la metodología Fire Assay (Vía Seca) resultando un contenido de oro de 80,76. Los resultados se detallan en la tabla 5.

Tabla 5. Resultado del análisis Fire Assay.

\begin{tabular}{cc}
\hline $\begin{array}{c}\text { ID Muestras } \\
\text { Lab }\end{array}$ & $\begin{array}{c}\text { Elemento } \\
\text { Químico }\end{array}$ \\
\hline Elementos & $\mathrm{Au}$ \\
Unidades & $\%$ \\
LC Inf. & 5 \\
LC Sup. & 150 \\
Muestra & 80,76 \\
\hline
\end{tabular}

\section{Análisis de oro remanente en la arenilla}

La muestra de solución del lixiviado de oro cianurado se analizó por espectrofotometría de absorción atómica (EAA), obteniéndose un valor de $98 \mathrm{mg} \mathrm{L}^{-1}$ de contenido de oro, en consecuencia, el oro remanente que queda en la arenilla después de la separación en mesa gravimétrica fue de $0.196 \mathrm{~g} \mathrm{~kg}^{-1}$ de arenilla.

La eficiencia de separación de la mesa gravimétrica, considerando el oro total obtenido y el peso de arena aluvial tratado fue de:

$0.196 \mathrm{~g} \mathrm{Au}$ remanente en arena / $(0.860+0.196) \mathrm{g}(100)=18.5 \%$ Au no recuperado Eficiencia de separación de la mesa gravimétrica $=81.5 \%$ 


\section{Caracterización electroquímica - estudio de la corrosión de oro patrón y parámetros de lixiviación}

\section{Caracterización electroquímica del oro patrón}

Se utilizó un electrodo de oro patrón $(99,95 \%)$ el cual fue caracterizado electroquímicamente mediante voltamperometría cíclica en $\mathrm{H} 2 \mathrm{SO} 40.1 \mathrm{~mol} \mathrm{~L}^{-1}$. En la figura 3 se muestra una voltamperometría típica de un electrodo de oro en medio ácido, en la cual se observa que a potenciales comprendidos entre 1.1-1.4 V aparece un hombro conformado por varios pequeños picos que se asocia a la formación de diferentes estados oxidados de oro, a potenciales superiores a 1.45 se descompone el agua formando oxígeno; aproximadamente a $1.0 \mathrm{~V}$, en el barrido catódico se forma un pico intenso de reducción de los óxidos de oro [10].

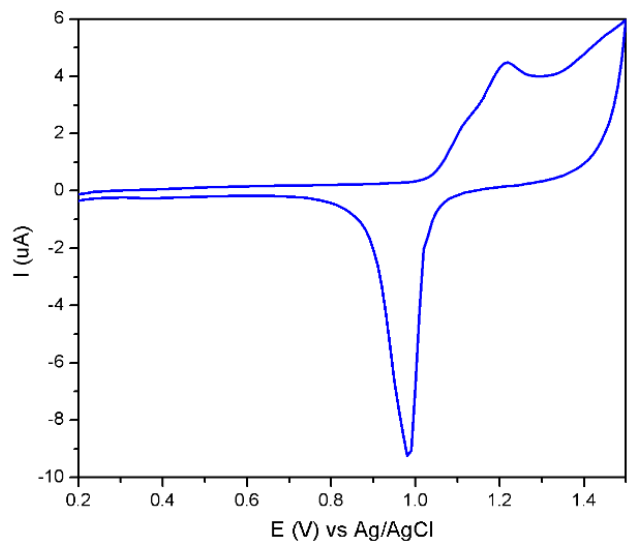

Figura 3. A) Muestra de arenilla. B) Imágenes de la muestra de arenilla con la lupa estereoscópica trinocular.

\section{Estudio de la lixiviación electroquímica del oro en $\mathrm{NaCl}$}

En la figura 4 se muestran los voltamperogramas cíclicos del electrodo de oro en el electrolito soporte de $\mathrm{Na}_{2} \mathrm{SO}_{4}$, al cual se le añade una solución de cloruro de sodio para establecer concentraciones de 1 a $10 \mathrm{~g} \mathrm{~L}^{-1}$. Los experimentos fueron realizados empleando el electrodo de referencia de $\mathrm{Ag} / \mathrm{AgCl}$ previo burbujeo de nitrógeno durante $10 \mathrm{~min}$.

Las respuestas voltamperométricas observadas en la figura 4 muestran el comportamiento típico de un fenómeno de lixiviación electroquímica del oro, el continuo crecimiento de la corriente es asociada a la cantidad de ion cloruro añadido mostrando la dependencia de la velocidad de electrolixiviación con la concentración de cloruro. El mecanismo de reacción ha sido discutido por J. Arvia et. $a l^{11}$, concluyendo que los productos anódicos son Au(I) y $\mathrm{Au}(\mathrm{III})$ dependiendo de la concentración y potencial de oxidación empleado, el mecanismo se ve favorecido por la espontánea adsorción del ion cloruro sobre el electrodo de oro. El 
último paso (Ec.3), muestra la desproporción espontánea del complejo $3\left(\mathrm{AuCl}_{2}^{-}\right)_{\mathrm{ad}}$ para formar la especie $\mathrm{AuCl}_{4}^{-}$estabilizándose en la solución. Las ecuaciones que la describen son:

$$
\begin{aligned}
& \mathrm{Au}+\mathrm{Cl}^{-} \leftrightarrow \mathrm{AuCl}_{\text {ad }}^{-} \quad \text { Ec. } 1 \\
& \mathrm{AuCl}_{a d}^{-}+\mathrm{Cl}^{-} \leftrightarrow\left(\mathrm{AuCl}_{2}^{-}\right)_{a d}+e^{-} \quad \mathrm{Ec} .2 \\
& 3\left(\mathrm{AuCl}_{2}^{-}\right)_{a d} \leftrightarrow \mathrm{AuCl}_{4}^{-}+2 \mathrm{Au}+2 \mathrm{Cl}^{-} \quad \text { Ec. } 3
\end{aligned}
$$

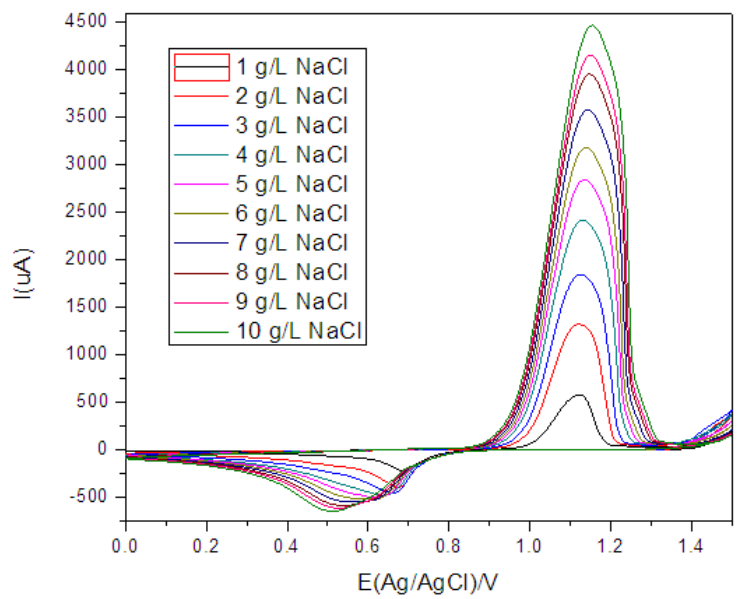

Figura 4. Voltamperometría cíclica del electrodo de oro en electrolito de $0.1 \mathrm{~mol} \mathrm{~L}^{-1} \mathrm{Na}_{2} \mathrm{SO}_{4}$, con variación de concentración de $\mathrm{NaCl}$ de $1 \mathrm{~g} \mathrm{~L}^{-1}$ a $10 \mathrm{~g} \mathrm{~L}^{-1} \cdot \mathrm{v}=100 \mathrm{mV} \mathrm{s}^{-1}$

\section{Estudio de la lixiviación electroquímica influenciada por el pH}

En la figura 5 se muestran las voltamperometrías cíclicas del oro en el sistema $\mathrm{NaCl}$ y a valores de $\mathrm{pH}$ variable de 2,3,4,5,7 ajustados, añadiendo $\mathrm{HCl} 1: 1$ y en electrolito de $\mathrm{NaCl} 10 \mathrm{~g} \mathrm{~L}^{-1}$. El gas de cloro en sus disoluciones acuosas también actúa formando tres especies oxidantes, dependiendo del $\mathrm{pH}$ en el que se encuentren: cloro acuoso $\left(\mathrm{Cl}_{2(\mathrm{ac})}\right)$, ácido hipocloroso $(\mathrm{HOCl})$ e iones hipoclorito $\left(\mathrm{ClO}^{-}\right)$. Estas especies se pueden generar por la adición de hipoclorito de sodio $(\mathrm{NaOCl})$ en solución ${ }^{12}$, estas sales se ionizan en agua, bajo condiciones ácidas $(\mathrm{pH}<$ 7.5) el ion hipoclorito se convierte en ácido hipocloroso. En condiciones muy ácidas $(\mathrm{pH}<$ $3.5)$ y en presencia de iones cloruro, se forma cloro acuoso. Todas las especies de cloro son potentes oxidantes pero el $\mathrm{HOCl}$ es el más eficaz. Por lo tanto, el $\mathrm{pH}$ debe ser mantenido en una gama de estabilidad del $\mathrm{HOCl}^{13}$. En la figura 5 se observa que el pico de corrosión para el oro en aproximadamente $1.2 \mathrm{~V}$ presenta mayor corriente de corrosión cuando el pH igual a 2. Por otro lado, se observa también que a $\mathrm{pH}$ igual a 7 se tiene una buena corrosión del oro, permitiendo lixiviar el oro en condiciones neutras a costa de disminuir la velocidad. 


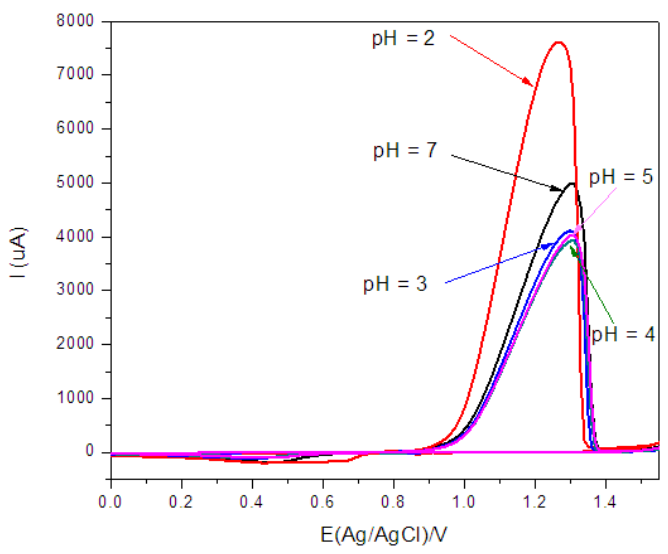

Figura 5. Voltamperometría cíclica para el $\mathrm{Au} / \mathrm{V}$ en el sistema $\mathrm{NaCl}-\mathrm{HCl}$. Concentración de $\mathrm{NaCl}$ de $10 \mathrm{~g} \mathrm{~L}^{-1}$ a pH 2, 3, 4, 5 y 7. $\mathrm{v}=100 \mathrm{mV} \mathrm{s}^{-1}$, último ciclo.

En la figura 6 se muestran las voltamperometrías cíclicas del oro en el sistema $\mathrm{NaCl}-\mathrm{HCl}-$ $\mathrm{NaClO}$ en presencia de $\mathrm{N}_{2}$, teniendo como concentración fija de $\mathrm{NaCl} 10 \mathrm{~g} \mathrm{~L}^{-1}$ y NaClO $40 \mathrm{~g}$ $\mathrm{L}^{-1}$ a la cual se adicionó cantidades de $\mathrm{HCl}$ concentrado para adecuar el $\mathrm{pH}$ a 4, 3 y 2 .

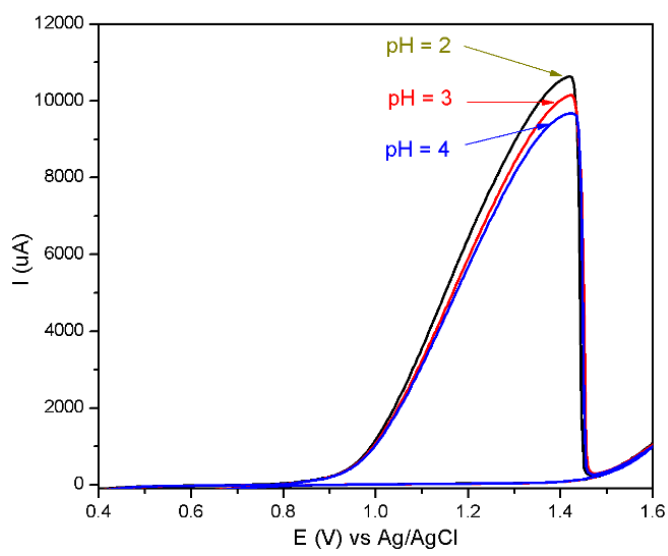

Figura 6. Voltamperometría cíclica para el $\mathrm{Au} / \mathrm{V}$ en el sistema $\mathrm{NaCl}-\mathrm{NaClO}-\mathrm{HCl}$. Concentraciones de $\mathrm{NaCl}$ de $10 \mathrm{~g} \mathrm{~L}^{-1}, \mathrm{NaClO}$ de $40 \mathrm{~g} \mathrm{~L}^{-1}$ a pH 2, 3 y $4 . \mathrm{v}=100 \mathrm{mV} \mathrm{s}^{-1}$, último ciclo.

En este caso, el electrolito base contiene una cantidad importante de $\mathrm{NaClO}$ que le permite lixiviar químicamente el oro, de tal modo que la electrolixiviación actúa simultáneamente a la reacción química obteniendo una mayor velocidad neta. En este caso la corriente asociada a pH 2 es de $10.7 \mathrm{~mA}$ comparado con el valor de $7.7 \mathrm{~mA}$ en ausencia de $\mathrm{NaClO}$ (figura 5) 
Las reacciones químicas de lixiviación de oro pueden ser escritas ${ }^{14}$ :

$$
\begin{array}{lr}
2 \mathrm{Au}+3 \mathrm{Cl}_{2}+2 \mathrm{Cl}^{-} \rightarrow 2\left[\mathrm{AuCl}_{4}\right]^{-} & \text {Ec.4 } \\
2 \mathrm{Au}+3 \mathrm{HClO}+5 \mathrm{Cl}^{-}+3 \mathrm{H}^{+} \rightarrow 2\left[\mathrm{AuCl}_{4}\right]^{-}+3 \mathrm{H}_{2} \mathrm{O} & \text { Ec.5 }
\end{array}
$$

\section{Eficiencia de recuperación de oro patrón y de oro aluvial}

$\mathrm{El}$ oro patrón y el oro aluvial fueron lixiviados químicamente utilizando $\mathrm{NaCl} 10000 \mathrm{ppm}$, $\mathrm{NaClO} 40000$ ppm y ácido fosfórico a pH 2. La solución lixiviada resultado del proceso de disolución de oro aluvial mostró al final residuos sólidos y cierta turbidez, el cual se separó por filtración.

Las soluciones que contenían el oro aluvial y el oro patrón disuelto fueron tratadas con FeSO4, hasta precipitación total del oro. El oro obtenido fue secado a $120 \mathrm{oC}$ durante $2 \mathrm{~h}$ y se pesó comparándolo con el oro pesado inicialmente. En la tabla 6 se muestran los datos del proceso. El procedimiento presentado para la recuperación de oro aluvial nos reporta un valor de $99,89 \%$ de recuperación.

Tabla 6. Masas y porcentaje de eficiencia de oro patrón y oro aluvial.

\begin{tabular}{ccc}
\hline & Oro Patrón & Oro Aluvial \\
\hline Masa de oro inicial $(\mathrm{g})$ & 0.12512 & 0.14403 \\
Ley del oro & $99.95 \%$ & $80.76 \%$ \\
& 0.12505 & 0.11632 \\
Masa de oro recuperado $(\mathrm{g})$ & 0.12503 & 0.11620 \\
\% Eficiencia de recuperación & 99.93 & 99.89 \\
\hline
\end{tabular}

\section{Recuperación vía electroquímica}

La electrólisis para la electrodeposición de oro se realizó aplicando una densidad de corriente de $10 \mathrm{~mA} \mathrm{~cm}-2$ en agitación continua durante 1 h. Se logró recuperar el 93,52\% del contenido de oro. Los datos obtenidos antes y después del proceso de lixiviación se observan en la tabla 7.

Tabla 7. Masas y porcentaje de eficiencia de la electrodeposición de oro.

\begin{tabular}{cc}
\hline Parámetro & Resultado \\
\hline Masa de placa de acero inicial $(\mathrm{g})$ & 29.16152 \\
Masa de oro recuperado $(\mathrm{g})$ & 29.24764 \\
Masa de oro recuperado $(\mathrm{g})$ & 0.08812 \\
\% Eficiencia de electrodeposición & 93.52 \\
\hline
\end{tabular}




\section{CONCLUSIONES}

La arena aluvial muestreada en la concesión minera "La Familia" del bajo Puquiri presenta un contenido mineralógico constituido principalmente de cuarzo, zircón, ilmenita y otros constituyentes de óxidos hierro. El concentrado tiene un contenido de oro de $0,86 \mathrm{~g} \mathrm{~kg}-1 \mathrm{de}$ arena aluvial y la ley es de $86,76 \%$. La mesa gravimétrica logra separar hasta el $81,5 \%$ del oro dejando en la arena 18,5\% de oro en forma de partículas finas. Los estudios electroquímicos de lixiviación del oro de la arena aluvial empleando una solución de $\mathrm{NaCl}$ solo y $\mathrm{NaCl} /$ $\mathrm{NaClO}$ combinado muestra que el hipoclorito tiene un fuerte poder oxidante capaz de lixiviar químicamente el contenido de oro de las arenas aluviales.

Los ensayos comparativos de recuperación de oro de la solución lixiviada de oro (oro patrón y oro aluvial) empleando solución de sulfato ferroso en medio ácido, muestran una alta eficiencia, recuperándose entre 99,93 y 99,89\% del contenido de oro, respectivamente. La escasa diferencia de ambos valores muestra que no existe inhibidores químicos en los minerales que acompañan al oro en las arenas aluviales. La recuperación de oro también es posible mediante electrodeposición de la solución lixiviada, sin embargo, para lograr una eficiencia equivalente a la obtenida en la precipitación química se debe emplear un exceso de hasta dos veces la carga estequiométricamente necesaria para su recuperación.

\section{AGRADECIMIENTOS}

Los autores expresan su gratitud a CIENCIACTIVA, CONCYTEC y FONDECYT por el apoyo financiero otorgado para el desarrollo de esta investigación a través del proyecto FONDECYT Contrato 209-2015

\section{REFERENCIAS BIBLIOGRÁFICAS}

1. Yard EE, Horton J, Schier JG, Caldwell K, Sanchez C, Lewis L, et al. Mercury exposure among artisanal gold miners in Madre de Dios, Peru: a cross-sectional study. J Med Toxicol. 2012; 8 (4): 441-448.

2. Swenson JJ, Carter CE, Domec JC, Delgado CI. Gold Mining in the Peruvian Amazon: Global Prices, Deforestation, and Mercury Imports. PloS One. 2011; 6 (4): e1875. doi: 10.1371/journal.pone.0018875.

3. Senanayake G. Gold leaching in non-cyanide lixiviant systems: critical issues, on fundamentals and applications. Miner Eng. 2004; 17: 785-801.

4. Ghobeiti Hasab M, Rashch F, Raygan Sh. Chloride-hypochlorite leaching and hydrochloric acid washing in multi-stages for extraction of gold from a refractory concentrate. Hydrometallurgy. 2014; 142: 56-59.

5. Tran T, Lee K, Kapila F. Halide as an alternative lixiviant for gold processing - an update. En: Young CA, Twidwell LG, Anderson CG. Meeting, Cyanide: where to from 
here; 2001; New Orleans, LA. Pittsburgh, PA: The Minerals Metals \& Metal Society; 2001. P. 501-508.

6. Soo Na K, Hi Jung B, Woong J, Jun Ha T, Tran T, Jun Kim M. Use of chloridehypochlorite leachants to recover gold from tailing. Int J Miner Process. 2008; 86: 131 140.

7. Ghobeiti Hasab M, Raygan S, Rashchi F. Chloride-hypochlorite leaching of gold from a mechanically activated refractory sulfide concéntrate. Hydrometallurgy. 2013;138: 59-64.

8. Ghobeiti Hasab M, Rashchi F, Raygan S. Simultaneou, sulfide oxidation and gold leaching of a refractory gold concentrate by chloride-hypochlorite solution. Miner Eng. 2013; 50-51: 140-142.

9. de Andrade Lima LRP, Bernardez LA, Barbosa LAD. Characterization and treatment of artisanal gold mine tailings. J Hazard Mater. 2008; 150(3): 747-753.

10. Ma W, Lun Ying Y, Xia Qin L, Gu Z, Zhou H, Wei Li D, et al. Investigating electrontransfer processes using a biomimetic hybrid bilayer membrane system. Nat Protocol. 2013; 8: 439-450.

11. Herrera Gallego J, Castellano CE, Calandra AJ, Arvia AJ. The electrochemistry of gold in acid aqueous solutions containing chloride ions. J Electroanal Chem Interf Electr 1975; 66(3): 207-230.

12. Puvvada GVK, Murthy DSR. Selective Precious Metals Leaching from a chalcopyrite Chloride/Hypochlorite Media. Hydrometallurgy. 2000; 58: 185-191.

13. Black and Veatch Corporation. White's handbook of chlorination and alternative disinfectants, 5th Edition. New York: John Wiley \& Sons; 2010. p. 68-131.

14. Baghalha M. Leaching of an oxide gold ore with chloride/hypochlorite solutions. Int J Miner Process. 2007; 82: 178-186. 